RESEARCH PAPER

\title{
Effect of Addition of Additives on Sequential Culture Lactic Acid Fermentation of Radish
}

\author{
Somesh Sharma and V.K. Joshi* \\ School of Bioengineering and Food Technology, Shoolini University, Solan, Himachal Pradesh, India \\ *Corresponding author: vkjoshipht@rediffmail.com
}

Paper No.: 237

Received: 18-07-2019

Revised: 14-10-2019

Accepted: 24-11-2019

\begin{abstract}
Spices or aromatic herbs are added to most of the lactic acid fruit and vegetable fermentation preparations to improve the flavour of the finished products. Aromatic compounds in these spices (including mainly terpenes and polyphenols) often have an antimicrobial effect which means that they can exert a selective role in the growth and activity of microorganisms during fermentation. Hence, investigations were carried out to study the effect of different additives on the lactic acid fermentation of radish. It was concluded from the studies that the acid production pattern in sequential lactic acid fermentation of radish are influenced by the addition of additives. There were also differences in acid production right from the beginning and differences were quite evident after 5 days of fermentation on addition of mustard as compared to other additives. It is clearly evident that addition of 2 per cent mustard produced the highest titratable acid. The addition of mustard seeds correspondingly enhanced the lactic acid bacterial count along with the titrtable acidity. Amongst the interactions, mustard ( 2 per cent) had the lowest $(0.18 \%)$ reducing sugar followed by mustard 1 per cent. Based on the reducing sugar concentration it is concluded that it is concluded that, the use of mustard seeds had enhanced the fermentability of sugar into lactic acid. The low alcohol content in treatment with 2 per cent mustard might be due to its influence on the selective growth of lactic acid bacteria in mustard and its antimicrobial effect on other microorganisms thus, allowing lactic acid bacteria to grow and produce maximum lactic acid.
\end{abstract}

Keywords: Aromatic herbs, lactic acid, antimicrobial, fermentation, alcohol, bacteria, titratable acid

Among the different methods, preservation by fermentation is well known. It is one of the oldest method of food preservation in the world (Pederson, 1979). Although China is believed to be the birth place of the process of fermented vegetables, the preservation by fermentation began before the recorded history (Joshi and Thakur, 2000). Fermentation using natural or starter culture has emerged to be a cheap method of preservation to increase the shelf-life of the products, besides preparation of new products with diversified taste and flavour. Lactic acid fermentation is used for commercial bulk storage of seasonal vegetables to increase their availability and to obtain a desired sensory quality of products (Frazier and Westhoff, 1998). This process apart from contributing certain desirable physical and flavour characteristics, ensures the availability of products at relatively low cost. If some of these fermented products can be made into food products which are being consumed or are nutritionally or microbiologically more stable, still retaining the advantages of lactic acid fermentation, it would be the most appropriate approach.

Fermented foods are more nutritious and have better

How to cite this article: Sharma, S. and Joshi, V.K. (2019). Effect of Addition of Additives on Sequential Culture Lactic Acid Fermentation of Radish. Int. J. Food Ferment. Technol., 9(2): 133-138.

Source of Support: None; Conflict of Interest: None 
acceptability than unfermented ones (Joshi et al. 1999; Sahlin, 1999; Hang and Jackson, 1967). One of the reasons for the increasing interest in fermented foods now-a-days is their recognition to promote the functions of the human digestive system in a number of positive ways. In 1900, Metchnikoff pointed out the use of fermented milk in the diet for prevention of certain diseases of the gastrointestinal tract and promotion of healthy day-to-day life. Since then, a number of studies have shown that the fermented food products do have a positive effect on health (Sahlin, 1999).

In recent years, increase in consumers demand for fresh like products, containing natural ingredients, changing food patterns and convenience have led to the development of minimally processed products using $\mathrm{LAB}$ culture. Lactic acid fermentation using LAB cultures is employed for the preparation of different products such as fermented grape juice, sauces, ready-to-serve drink, instant chutney, fermented peanut milk, sogurt, fermented corn meal Kuhunzaki, fermented radish pickle, and fermented beverages from wheat and maize (Joshi and Thakur, 2000; Joshi and Sharma, 2009; Sharma et al. 2008; Joshi et al. 2011). Kimchi and sauerkraut are the well known products made by fermenting vegetables. Some of these fermented foods have established a reputation of being beneficial to human health. Although, all food items contain different types of microorganisms and in different population, which microorganisms would dominate depends upon several factors. Sometimes, microorganisms are initially present in a very low number in the food, for example, lactic acid bacteria (LAB) in the favorable conditions, will outnumber the other organisms especially those of public health significance, inhibiting their growth. In contrast to fermented meat, fish, dairy and cereal products, fermented vegetables have not been recorded as a significant source of microbial food poisoning (Fleming and McFeeters, 1981). Several studies have shown improved nutritional value in grains as a result of lactic fermentation, principally through enhancement of essential amino acids. Further, fermentation of plant products reduces levels of anti-nutritional factors present in the natural produce. Bacteriocins produced during lactic acid fermentation of fig have been also reported as a biopreservative (Kumari et al. 2018).

In principle, most vegetables can be LAB fermented but, so far only beets, turnip, cauliflower, radish, carrot, cabbage, olives and cucumber are fermented on commercial scale for human consumption. However, only a few reports are available on LAB fermentation of carrot, radish and cucumber. Most of the studies have concentrated on the vegetables mentioned earlier using natural fermentation. Employing inoculated fermentation and investigating their sequence, and finally the physico-chemical and sensory quality would be an interesting aspect for more investigation both academically and practical utility point of view. Sharma and Joshi (2007) studied the influence of temperature and salt concentration on lactic acid fermentation of radish (Raphnus sativus). Even some of the studies done on probiotics reflected that these Lactic acid bacteria can also be probiotic and can be used in fruit juices after microencapsulation (Oberoi et al. 2019).

Spices or aromatic herbs are added to most of the lactic acid fruit and vegetable fermentation preparations to improve the flavour of finished products. Aromatic compounds in these spices (including mainly terpenes and polyphenols) often have an antimicrobial effect thus, they can have a selective role in the development of bacteria during fermentation. In the present investigations, effect of addition of different additives \{lactose, magnesium sulphate, manganese sulphate and mustard (Brassica juncea) on the LAB sequential culture fermentation was studied and the results have been discussed here.

\section{MATERIALS AND METHODS}

\section{Lactic acid bacterial strains}

The strains of Lactic acid bacteria (LAB) were procured from National Dairy Research Institute (NDRI), Karnal used in the study were Lactobacillus plantarum (NCDC 020), Pediococcus cerevisiae (NCDC 038) and Streptococcus lactis var diacetylactis (NCDC 061). These strains were first activated in MRS 
broth for $24-32 \mathrm{hrs}$ at temperature of $30-37^{\circ} \mathrm{C}$. After activation, these were maintained on MRS agar slants under refrigerated condition and were re-cultured after every three months from the stock cultures.

\section{Sequential fermentation}

In sequential fermentation, three different microorganisms were added as starter culture in sequence. Streptococcus lactis was added after $24 \mathrm{hrs}$ of fermentation and after about $48 \mathrm{hrs}$ Pediococcus cerevisiae was added and then, after 72 hrs Lactobacillus plantarum was added at the rate of 2 per cent each.

\section{Experimental setup}

The radish procured from the local market were washed, peeled and grated. To study the effect of additives, addition of different additives viz. lactose ( 1 and 2 per cent), mustard grounded ( 1 and 2 per cent) and magnesium sulphate + manganese sulphate ( 1 and 2 per cent) in combination were added to the grated radish along with 2.5 per cent salt. The fermentation was carried out at $26^{\circ} \mathrm{C}$ with sequential culture as starter culture. During fermentation, acid production pattern was recorded. On completion of fermentation when no further increase in acidity took place, the fermented vegetables were filled in sterilized glass jars. Hot brine was added and the jars were exhausted to expel the air inside the product to avoid any oxidation process during the storage period. The packed product was then, pasteurized at temperature of $71^{\circ} \mathrm{C}$ for $15 \mathrm{~min}$.

\section{Analysis}

\section{Chemical Analysis}

Titratable acidity was estimated by treating a known aliquot of the sample against $\mathrm{N} / 10 \mathrm{NaOH}$ solution using phenolphthalein as an indicator as per the standard method (A.O.A.C. 1980).

The $\mathrm{pH}$ was taken with HPG, G-2004 pH meter, after calibrating it with buffer solutions of $\mathrm{pH} 4$ and 9.2 (Ranganna, 1986).

Determination of reducing sugars was based on
Nelson-Somogy method (Sadasivam and Manickam, 1996). Diluted sample was heated with alkaline copper tartrate reagent $(1 \mathrm{ml})$, which is reduced to form cuprous oxide. Treated sample solution was boiled for 10 mins and cooled, arsenomolybdate $(1 \mathrm{ml})$ was added, which resulted in blue colour development. The colour was compared with a set of standards (glucose, 10-100 $\mu \mathrm{g}$ ) in a spectrophotometer-20D, by measuring absorbance at $520 \mathrm{~nm}$.

The calculations were made as per the standard curve in terms of glucose.

\section{Lactic acid Bacterial Count}

Lactic acids bacterial (LAB) count was taken according to the method given by Harrigan and McCance (1996). MRS agar media was prepared as per the composition and count was taken after incubation at $32^{\circ} \mathrm{C}$ depending upon the type of microorganism for 48-72 hrs and the number of microbial colony forming units as $\log \mathrm{CFU} / \mathrm{g}$ or $\mathrm{ml}$ of product was recorded.

\section{Statistical analysis}

The data of quantitative estimation of various chemical characteristics of different fermented products were anlaysed by Completely Randomized Design (CRD) while the data of sensory evaluation were analysed by Randomized Block Designs (RBD) as described by O'Mahony (1985).

\section{RESULTS AND DISCUSSION}

The results depicted in Fig. 1 show the acid production pattern in sequential lactic acid fermentation of radish as influenced by the addition of additives. There were differences in acid production right from the beginning due to addition of various additives. It is also clearly evident that addition of 2 per cent mustard produced the highest titratable acid. The differences were prominent after 5 days of fermentation on addition of mustard as compared with other additives.

The results (Table 1) on the physico-chemical characteristics showed significant differences in the titratable acidity among the various treatments, their 
Table 1: Effect of addition of additives on sequential culture lactic acid fermentation of radish

\begin{tabular}{llllll}
\hline Treatment & Conc. (\%) & Titratable acidity (\% LA) & pH & Reducing sugars (\%) & Alcohol (\% v/v) \\
\hline Lactose & 1 & 0.89 & 3.35 & 0.35 & 0.031 \\
& 2 & 0.97 & 3.39 & 0.31 & 0.044 \\
& Control & 0.94 & 3.41 & 0.39 & 0.049 \\
& Mean & 0.93 & 3.38 & 0.35 & 0.041 \\
\hline Mustard & 1 & 1.12 & 3.29 & 0.23 & 0.028 \\
& 2 & 1.26 & 3.20 & 0.18 & 0.021 \\
& Control & 0.94 & 3.41 & 0.39 & 0.049 \\
& Mean & 1.10 & 3.30 & 0.26 & 0.032 \\
\hline MgSO $_{4}+\mathrm{MnSO}_{4}$ & 1 & 1.10 & 3.29 & 0.32 & 0.047 \\
& 2 & 0.96 & 3.26 & 0.35 & 0.042 \\
& Control & 0.94 & 3.41 & 0.39 & 0.049 \\
& Mean & 1.00 & 3.32 & 0.35 & 0.046 \\
\hline Mean conc. & 1 & 1.03 & 3.31 & 0.30 & 0.035 \\
& 2 & 1.06 & 3.28 & 0.28 & 0.035 \\
${ }^{*}$ Initial characteristics & Control & 0.94 & 3.41 & 0.39 & 0.049 \\
\hline CD $(\leq 0.05)$ & & 0.16 & 5.87 & 2.10 & - \\
Treatment $(\mathrm{T})$ & & & & $\mathrm{N}$ \\
Concentration $(\mathrm{C})$ & & 0.034 & 0.032 & 0.027 & $\mathrm{NS}$ \\
$\mathrm{T} \times \mathrm{C}$ & 0.034 & 0.032 & 0.027 & $\mathrm{NS}$ \\
\hline
\end{tabular}

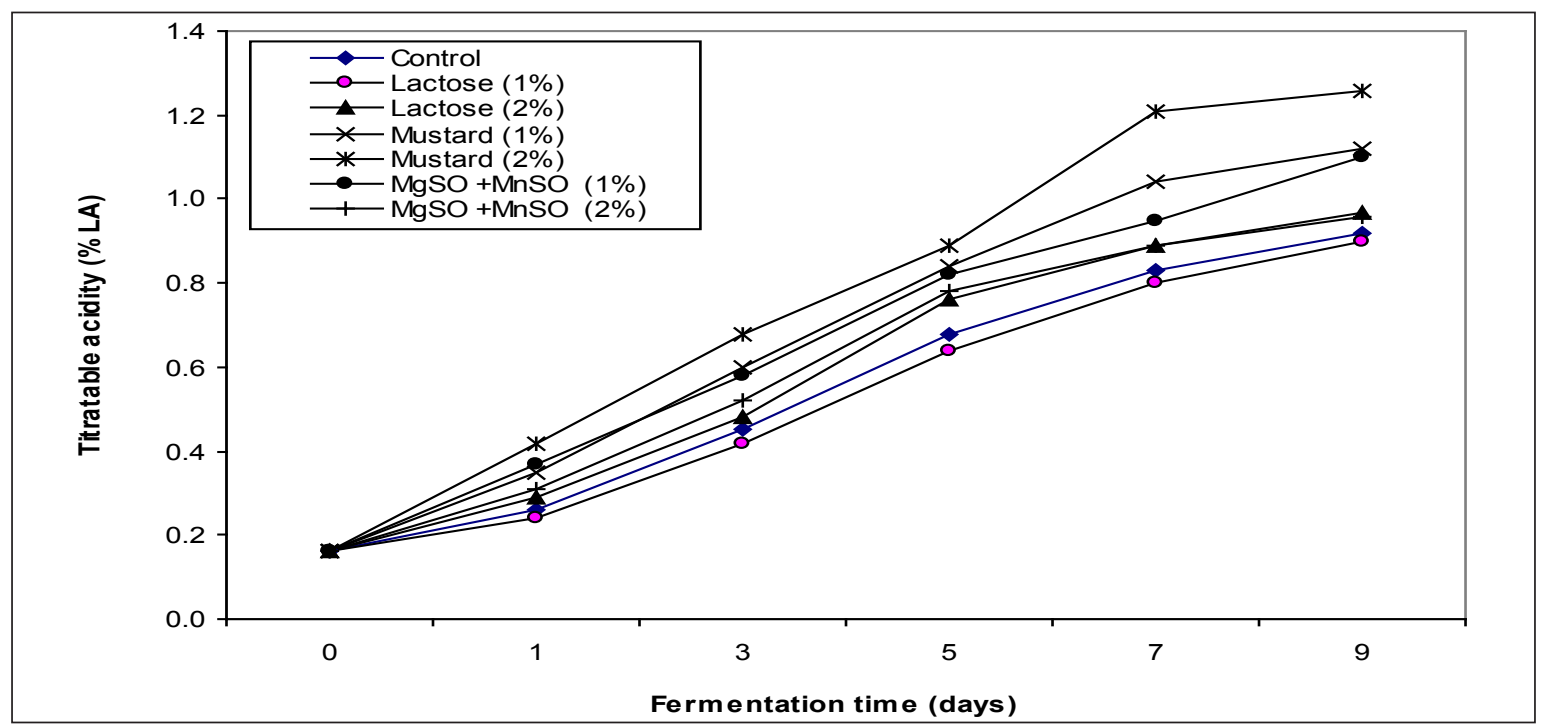

Fig. 1: Acid production pattern in sequential LAB fermentation of radish by addition of additives

concentration and the control. The titratable acidity ranged from 0.89 to 1.26 per cent. The highest $(1.10 \%$ LA) titratable acidity was recorded in the treatment where mustard was added. Amongst the interactions, the highest titratable acidity $(1.26 \%)$ was found in fermentation where 2 per cent mustard was added and the minimum titratable acidity was documented in the control. It is clear that addition of additives had certainly increased the titratable acidity of fermented radish. The results are in consistence with the earlier results of acid production pattern. Our results are also consistent with the earlier findings (Anand and 
Das, 1971) indicating that adding 6-10 g of mustard seed powder to turnip increased the lactic acid levels during fermentation. The results in Fig. 2 depicted the lactic acid bacteria (LAB) count in sequential culture fermentation of radish on addition of additives. It is clear that on addition of mustard, the lactic acid bacteria (LAB) count was more and corresponded to that titratable acidity. But the concentration 1 and 2 per cent did not effect the lactic acid bacterial (LAB) population. However, the lactic acid bacterial (LAB) count was comparable with other additives used in the fermentation.

The results (Table 1 ) reveal that $\mathrm{pH}$ values varied from 3.41 to 3.20. Among the treatments, the lowest (3.30) $\mathrm{pH}$ value was obtained in mustard and the highest (3.41) in control. However, among the interaction's lowest $\mathrm{pH}$ value (3.20) was recorded in treatment with 2 per cent mustard and highest (3.41) in the control. The $\mathrm{pH}$ values obtained are in corroboration with earlier results of titratable acidity. It is also discernible from the results that reducing sugar content ranged between 0.18 to 0.39 per cent.
Amongst the interactions, mustard 2 per cent had the lowest $(0.18 \%)$ reducing sugar followed by mustard 1 per cent. Based on the reducing sugar concentration, it can be stated that the use of mustard had enhanced the fermentability of sugar into lactic acid.

During lactic acid bacterial (LAB) fermentation, the alcohol content ranged from 0.021 to 0.049 per cent with highest $(0.049 \%)$ alcohol content in control and lowest $(0.021 \%)$ in treatment with mustard 2 per cent. Further, amongst the treatments mustard addition had lowest $(0.035 \%)$ alcohol content. It is desirable as the sugar was not diverted to alcohol production but was converted into lactic acid. However, the highest $(0.58 \%)$ alcohol content was found in lactic acid fermentation of radish with addition of lactose. The low alcohol content in treatment with 2 per cent mustard might be due to its influence on the selective growth of lactic acid bacteria in treatment with mustard and its antimicrobial effect on other microorganisms thus, allowing lactic acid bacteria to grow and produce maximum lactic acid. It has been found that mustard seeds contain a volatile aromatic

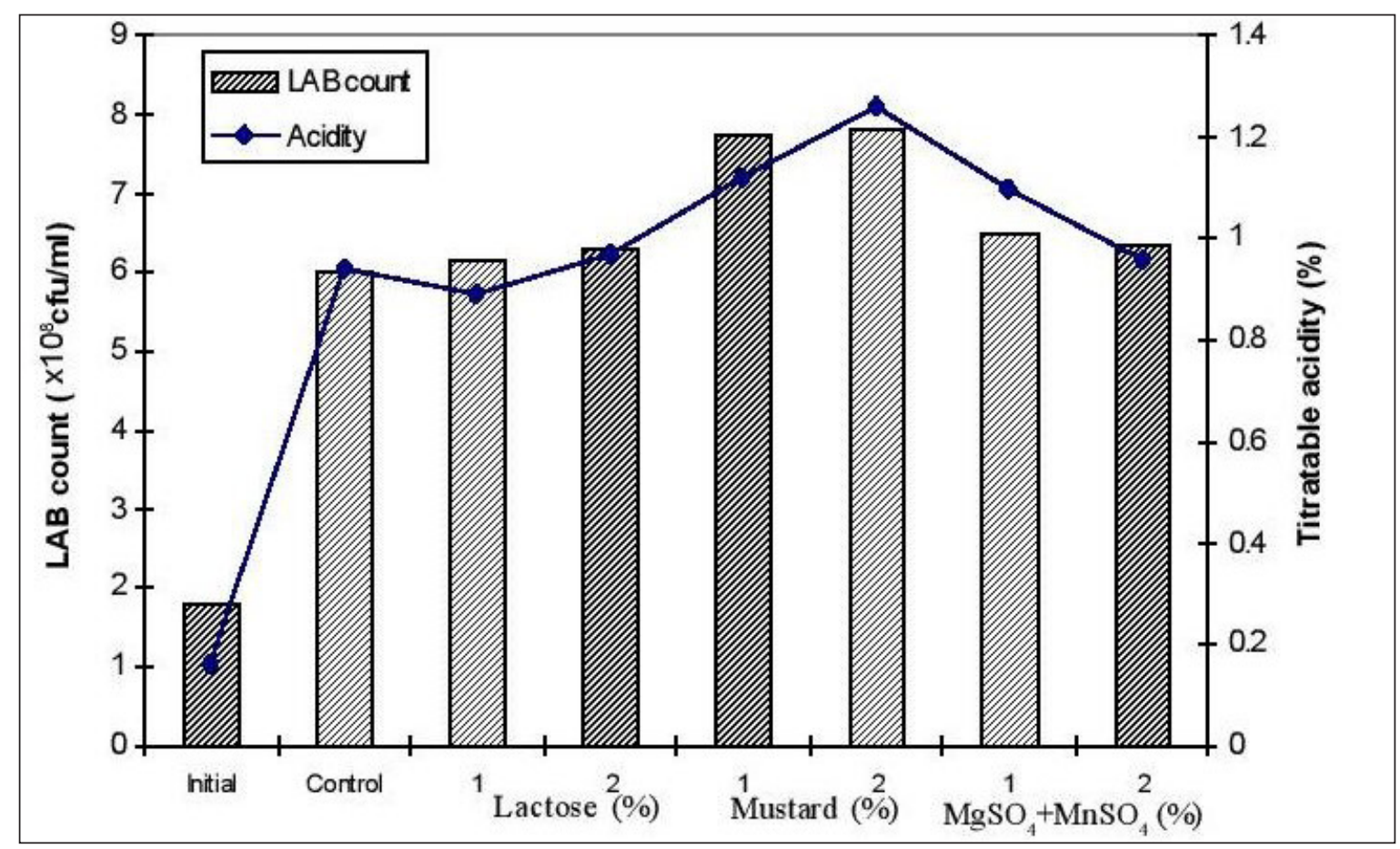

Fig. 2: Variation in LAB count and acid production on addition of additives during radish sequential culture fermentation 
compound with antibacterial and antifungal properties (Anand and Das, 1971) and there it has been shown to have a selective preservative action, allowing lactic acid bacteria (LAB) to grow and suppress the surface yeasts (Sethi and Anand, 1984). The results are in corroboration with the results of lactic acid bacteria (LAB) count.

\section{REFERENCES}

A.O.A.C. 1980. Official Methods of Analysis. Association of Official Analytical Chemists, W. Hortwitz (ed.). $13^{\text {th }}$ edn. Washington DC.

Anand, J.C. and Das, L. 1971. Effects of condiments on lactic fermentation in sweet turnip pickle. J. Food Sci. Technol., 8(3): 143.

Fleming, H.P. and Mc Feeters, R.F. 1981. Use of microbial cultures : vegetable products. Food Technol., 35(1): 84-88.

Frazier, W.C. and Westhoff, D.C. 1998. Food Microbiology. Tata Mcgraw Hill Publi. Co., $7^{\text {th }}$ edn, New Delhi.

Hang, Y.D. and Jackson, H. 1967. Preparation of soyabean cheese using lactic starter organisms-General characteristics of the finished cheese. Food Technol., 21: 1033.

Harrigan, W.F. and McCance, E.M. 1966. (eds.) Laboratory Methods in Microbiology. $2^{\text {nd }}$ edn. Academic Press, London.

Joshi, V.K. and Sharma, S. 2009. Preparation and evaluation of sauces from lactic acid fermented vegetables. J. Food Sci. Technol., 47(2): 214-218.

Joshi, V.K. and Sharma, S. 2009. Lactic acid fermentation of radish for shelf-stability and pickling. Natural Product Radiance, 8(1): 19-24.

Joshi, V.K., Bhutani, V.P. and Thakur, N.K. 1999. Nutrition and composition of fermented products. In: Biotechnology : Food Fermentation. V.K. Joshi and Ashok Pandey (eds.) Vol. I. Educational Publishers and Distributors, New Delhi, pp. 259.

Joshi, V.K. and Thakur, Shiwali. 2000. Lactic acid Fermented Beverage. In: Post-harvest Technology of Fruits and Vegetables. L.R. Verma, and V.K Joshi, Eds., pp. 1102-1127. The Indus Publ. New Delhi.

Joshi, V.K. and Bhat, Anju. 2000. Pickles: Technology of Preparation. In: Post-harvest Technology of Fruits and Vegetables. L.R. Verma and V.K. Joshi (eds.), Indus Publishing Co., New Delhi, pp. 777-798.
Joshi, V.K., Sharma Somesh, Chauhan Arjun and Thakur, N.S. 2011. Preparation and evaluation of instant chutney mix from lactic acid fermented vegetables. International Journal of Food and Fermentation Technology, 1(2): 201-209.

Kumari Kajal, Sharma Somesh and Kaundal Kirti. 2018. Production, purification and efficacy of bacteriocin isolated from natural lactic acid fermentation of wild Himalayan fig fruit. Journal of Pure and Applied Microbiology, 12(2): 879-885.

O'Mohony, M. 1985. Sensory Evaluation of Foods - Statistical Method and Procedures. Marcel Dekker Inc., New York.

Oberoi Khyati, Tolun Aysu, Sharma Kanika and Sharma Somesh. 2019. Microencapsulation: An Overview for the survival of probiotic. Journal of Microbiology, Biotechnology and Food Sciences, 9(2): 280-287.

Pederson, C.S. 1979. Microbiology of Food Fermentations. Second Edition, The AVI Publishing Co., Westport/ Connecticut (USA), pp. 384.

Ranganna, S. 1986. Handbook of Analysis of Quality Control for Fruit and Vegetable Products. $2^{\text {nd }}$ Edn. Tata McGraw Hill Publ. Co., New Delhi.

Sadasivam, S. and Manickam, A. 1996. Biochemical methods. $2^{\text {nd }}$ edn. New Age International, New Delhi.

Sahlin, P. 1999. Fermentation as a method of food processing: production of organic acids, $\mathrm{pH}$-development and microbial growth in fermenting cereals. Licentiate thesis, Division of the Applied Nutrition and Food Chemistry, Lund University.

Sethi, V. and Anand, J.C. 1984. Effect of mustard and its components on the fermentation of cauliflower. Indian Food Packer, 38(4): 41-46.

Sharma, S. and Joshi, V.K. 2007. Influence of temperature and salt concentration on lactic acid fermentation of radish (Raphnus sativus). J. Food Sci. Technol., 44(6): 611-614.

Sharma, S., Joshi, V.K. and Lal Kaushal, B.B. 2008. Preparation of Ready -to-Serve drink from lactic acid fermented vegetables. Indian Food Packer, 62(3): 17-21. 